\title{
Cookies de aveia adicionados de farinha da casca de abobrinha: análise físico-química e sensorial entre crianças
}

\section{Oatmeal cookies added zucchini peel flour: physico-chemical and sensory analysis among children}

Cookies de avena añadidos de harina de la cáscara de calabaza: análisis físico-químico y sensorial entre los niños

Ana Raíssa Orloski ${ }^{1}$ Marielli Barbosa dos Santos ${ }^{2}$ Elisvânia Freitas dos Santos ${ }^{3}$ Daiana Novello ${ }^{4}$

${ }^{1}$ Nutricionista, Universidade Estadual do Centro-Oeste (UNICENTRO), Campus CEDETEG. E-mail: anaraissaorloski@hotmail.com.br

${ }^{2}$ Nutricionista, Universidade Estadual do Centro-Oeste (UNICENTRO), Campus CEDETEG. E-mail: maribds12@hotmail.com.br

${ }^{3}$ Nutricionista, Doutora. Docente do Curso de Nutrição e do Programa de Pós-Graduação em Saúde e Desenvolvimento na Região CentroOeste da Universidade Federal de Mato Grosso do Sul (UFMS). E-mail: elisvania@gmail.com.br

${ }^{4}$ Nutricionista, Doutora. Docente do Curso de Nutrição e do Programa de Pós-Graduação Interdisciplinar em Desenvolvimento Comunitário da Universidade Estadual do Centro-Oeste (UNICENTRO), Campus CEDETEG.

E-mail: nutridai@gmail.com 
Resumo: O objetivo do estudo foi avaliar a aceitabilidade sensorial de cookies adicionados de Farinha da Casca de Abobrinha (FCA). Também, determinar a composição físico-química da formulação padrão e daquela contendo maior teor de FCA com aceitação semelhante ao padrão. Foram desenvolvidas 5 formulações de cookies: F1 (0\% FCA) e as demais adicionadas de 5\% (F2), 10\% (F3), 15\% (F4) e 20\% (F5) de FCA. Participaram da avaliação sensorial 70 provadores não treinados de 7 a 10 anos. Maiores notas foram verificadas para as amostras F1 e F2 $(p<0,05)$ em todos os atributos e para a aceitação global, sendo que não houve diferença estatística entre as demais amostras. Maiores teores de umidade, cinzas, proteínas, lipídios, calorias e fibras e menores de carboidratos foram verificados em F2. Conclui-se que um nível de adição de até 5\% de FCA em cookies foi bem aceito pelos provadores, obtendo-se boas expectativas de comercialização.

Palavras-chave: aceitabilidade; aproveitamento integral; nutrição; subproduto.

\begin{abstract}
The objective of the study was to evaluate the sensory acceptability of cookies added with Zucchini Peel Meal (ZPM). Also, determine the physico-chemical composition of the standard formulation and the one containing the highest ZPM content with similar acceptance to the standard. Five formulations of cookies were developed: F1 (O\% ZPM) and the others added $5 \%$ (F2), 10\% (F3), 15\% (F4) and 20\% (F5) of ZPM. A total of 70 untrained testers from 7 to 10 years participated in the sensory evaluation. Higher scores were observed for F1 and F2 samples $(p<0.05)$ in all attributes and for overall acceptance, and there was no statistical difference between the other samples. Higher levels of moisture, ashes, proteins, lipids, calories and fibers and lower carbohydrates were verified in F2. It was concluded that a level of addition of up to $5 \%$ of ZPM in cookies was well accepted by the tasters, obtaining good marketing expectations.
\end{abstract}

Keywords: acceptability; total utilization; nutrition; byproduct.

Resumen: El objetivo del estudio fue evaluar la aceptabilidad sensorial de cookies añadidos de la harina de la cáscara de calabaza (HCC). También, determinar la composición físicoquímica de la formulación estándar y de aquella conteniendo mayor contenido de HCC con aceptación semejante al estándar. Se desarrollaron 5 formulaciones de cookies: F1 (0\% HCC) y las demás agregadas de $5 \%$ (F2), 10\% (F3), 15\% (F4) y 20\% (F5) de HCC. Participaron de la evaluación sensorial 70 probadores no entrenados de 7 a 10 años. Se verificaron notas más grandes para las muestras F1 y F2 $(p<0,05)$ en todos los atributos y para la aceptación global, siendo que no hubo diferencia estadística entre las demás muestras. Los mayores contenidos de humedad, cenizas, proteínas, lípidos, calorías y fibras y menores de carbohidratos se verificaron en F2. Se concluye que un nivel de adición de hasta $5 \%$ de HCC en cookies fue bien aceptado por los probadores, obteniéndose buenas expectativas de comercialización.

Palabras clave: aceptación; aprovechamiento integral; nutrición; subproducto. 
Cookies de aveia adicionados de farinha da casca de abobrinha: análise físico-química e sensorial entre crianças

\section{INTRODUÇÃO}

Atualmente, a preocupação com o desperdício de alimentos tornou-se algo recorrente, pois representa um terço dos alimentos produzidos no mundo. Cerca de 1,3 bilhões de toneladas de alimentos são desperdiçados. No Brasil, cada habitante gera em torno de $1 \mathrm{~kg}$ de lixo/dia, sendo que $58 \%$ é lixo orgânico, o qual é basicamente formado por restos alimentares. Nesse caso, as frutas e hortaliças representam aproximadamente $30 \%$ e $35 \%$, respectivamente, das perdas. O desperdício ocorre quando o alimento é descartado intencionalmente, o que geralmente é causado devido ao reduzido prazo de validade, manuseio e/ou transporte inadequado, presença de malformações e durante as fases de distribuição, processamento e consumo (ORGANIZAÇÃO DAS NAÇÕES UNIDAS PARA A ALIMENTAÇÃO E A AGRICULTURA [FAO], 2013). Na maioria das vezes, verifica-se o descarte de cascas, talos e sementes, que ocorre durante o processo de pré-preparo e preparo dos alimentos.

Um número elevado de brasileiros vive em situação de extrema pobreza, contudo o aproveitamento integral dos alimentos como as cascas, talos e sementes poderia reduzir os custos com a alimentação. Além disso, melhorar o perfil nutricional da dieta, já que contém, em geral, elevados teores de fibras, vitaminas e minerais. Nesse contexto, muitas pesquisas vêm avaliando especificamente a adição de subprodutos de vegetais como as cascas de banana, chuchu e melancia para adição em diversos produtos como biscoitos, barra de cereais e cookies, obtendo boa aceitabilidade sensorial.

A abobrinha (Cucurbita Pepo L.) faz parte da família das cucurbitáceas e é caracterizada por ser uma hortaliça-fruta. Seu tamanho varia de 18 a 25 $\mathrm{cm}$, sendo que existem abobrinhas com cores que vão do verde escuro ao verde muito claro. Possui grande importância na economia do Brasil e boa aceitação comercial. Comumente, a abobrinha é produzida em todas as regiões brasileiras, durante os períodos do outono, primavera e no inverno em temperaturas amenas. Em 2011, foram produzidas 3.187.953 toneladas de hortaliças no estado do Paraná, sendo 1\% representado pela abobrinha (PARANÁ, 2013). Em geral, a abobrinha é consumida na forma in natura ou adicionada como ingrediente em bolos, pizzas, tortas salgadas, dentre 
outras preparações. Apesar do elevado consumo da abobrinha, sua casca é, geralmente, descartada, o que reduz a ingestão de nutrientes.

A literatura já demonstrou a viabilidade da produção, comercialização e consumo de farinhas obtidas de subprodutos de vegetais e frutas, visando aumentar seu shelf-life (PORTELA, 2009). Nesse caso, o processo de desidratação pode reduzir a deterioração dos produtos, aumentar a estabilidade, diminuir significativamente o volume das embalagens, o que também auxilia na fase de transporte. Dessa forma, ressalta-se a importância para o desenvolvimento de novos produtos adicionados de ingredientes alternativos, como a Farinha da Casca de Abobrinha (FCA).

A idade escolar é caracterizada por crianças com 7 a 10 anos de idade. Essa etapa é, geralmente, caracterizada por um lento crescimento e desenvolvimento, porém constante, o que compreende uma maior demanda energética e de nutrientes. Comumente, essa fase é afetada pela mudança do estilo de vida e na alimentação, o que é influenciado por hábitos de colegas e amigos da escola. Nesse caso, verifica-se um aumento no consumo de alimentos industrializados, com elevados teores em gorduras e açúcares e uma redução na ingestão de alimentos fonte de fibras, vitaminas e minerais como as frutas e vegetais. Com isso, pode haver o aumento no risco de desenvolvimento de diversas doenças crônicas não transmissíveis, como a diabetes mellitus e hipertensão arterial sistêmica, tanto na infância como nas fases futuras da vida. Considerando esse contexto, tornam-se necessárias pesquisas que avaliem novos produtos alimentícios que contenham elevados teores de nutrientes, como as vitaminas e minerais, visando colaborar para um consumo alimentar mais saudável na fase escolar.

Segundo a Associação Brasileira das Indústrias de Biscoitos, Massas Alimentícias e Pães \& Bolos Industrializados (ABIMAPI, 2016), existem mais de 200 tipos de biscoitos, sendo eles salgados, doces, recheados, cobertos etc. Os produtos de panificação apresentam uma ampla variedade, baixo custo e facilidade no preparo, assim possuem elevado potencial para a adição de novos ingredientes. No Brasil, a indústria de biscoitos registrou um crescimento de 7,1\% em 2015 comparado a 2014. A produção anual foi de 1,7 milhão de toneladas, com consumo per capita de 8,5 kg/ano e faturamento de $\mathrm{R} \$ 21$ bilhões. Os cookies são conceituados como produtos 
elaborados a partir da combinação de farinha(s), amido(s) ou fécula(s) dentre outros ingredientes, sujeitos ao amassamento e cocção, podendo ou não ser fermentados. Apresentam um longo shelf-life, além de boa aceitabilidade por crianças e adultos, sendo utilizado em diversas pesquisas com intuito de aprimorar seu valor nutricional. Apesar disso, esses alimentos possuem elevados teores de calorias e gorduras. Dessa forma, a introdução de ingredientes mais saudáveis em biscoitos e similares pode auxiliar na elaboração e consumo de alimentos mais nutritivos pela população em geral.

Para que seja possível a comercialização de novos produtos alimentícios, é essencial a utilização de testes científicos que avaliem suas diversas características tecnológicas, sensoriais e físico-químicas. Testes sensoriais são aplicados no desenvolvimento e melhoramento de produtos, testes de mercado, dentre outros, sendo que a boa aceitabilidade pode incentivar sua comercialização no mercado. Já os testes físico-químicos permitem conhecer a composição do produto alimentício, o que é essencial para a elaboração da tabela nutricional. Além disso, podem avaliar se as características exigidas pela legislação brasileira estão adequadas. Sabendo-se disso, o objetivo deste trabalho foi avaliar a aceitabilidade sensorial de cookies adicionados de diferentes níveis de FCA entre crianças. Também, determinar a composição físico-química do produto tradicional e daquele com maior teor de FCA e aceitação semelhante ao padrão.

\section{MATERIAIS E MÉTODOS}

Os ingredientes foram adquiridos em supermercados localizados no município de Guarapuava, PR. Foram utilizadas abobrinhas (Cucurbita Pepo L.) de cor verde clara, com melhor aspecto visual, superfície lisa sem imperfeições e de tamanho médio.

Inicialmente, 80,2 kg de abobrinha foram higienizadas em água corrente potável, sanitizadas (1 litro de água para $10 \mathrm{ml}$ de água sanitária, por 15 minutos), e novamente higienizados em água corrente potável. Em seguida, as cascas $(9,90 \mathrm{~kg}$ ) foram extraídas de forma manual com o auxílio de um descascador doméstico, sendo picadas em tamanho aproximado de $5 \mathrm{~cm}$. Em seguida, foram acomodadas em bandejas $(42 \times 60 \mathrm{~cm})$ de telas plásticas tipo treliça e submetidas à secagem em desidratador (Pardal ${ }^{\circledR}$, 
Brasil), com circulação de $\operatorname{ar}\left(70^{\circ} \mathrm{C}\right)$ por 24 horas. Depois de desidratadas permaneceram em temperatura ambiente $\left(22^{\circ} \mathrm{C}\right)$ até total resfriamento. Para o preparo da farinha, as cascas secas foram trituradas em liquidificador doméstico (Britânia ${ }^{\circledR}$, Brasil) e passadas em peneira com abertura de $0,5 \mathrm{~mm} / 32$ mesh (Bertel ${ }^{\circledR}$, Brasil) até a obtenção da FCA, que obteve um rendimento de $0,47 \mathrm{~kg}$.

Foram elaboradas 5 formulações de cookies, sendo: F1 padrão (0\%) e as demais adicionadas de 5\% (F2), 10\% (F3), 15\% (F4) e 20\% (F5) de FCA. Esses níveis de adição foram definidos por meio de testes sensoriais preliminares realizados com o produto. Além das porcentagens de FCA, os seguintes ingredientes foram utilizados nas formulações: aveia em flocos (31,14\%), farinha de trigo (F1: 27\%, F2: 22\%, F3: 17\%, F4: 12\% e F5: 7\%), açúcar mascavo $(19,47 \%)$, manteiga sem sal $(11,68 \%)$, ovos $(8,76 \%)$, canela em pó $(0,97 \%)$ e fermento em pó químico $(0,97 \%)$.

Inicialmente, foram misturadas em batedeira doméstica (Arno ${ }^{\circledR}$, Brasil) a manteiga e o açúcar mascavo até se obter uma massa homogênea. Em seguida, adicionaram-se os ovos, a farinha de trigo, a canela em pó, o fermento e a aveia em flocos, sendo misturados até completa homogeneização. Os cookies foram moldados de forma manual (2 cm de diâmetro) e distribuídos em assadeira de alumínio, coberta com papel manteiga. Em seguida, os biscoitos foram assados em forno industrial (Tedesco ${ }^{\circledR}$, Brasil), pré-aquecido $\left(180^{\circ} \mathrm{C}\right)$, por aproximadamente 15 minutos.

Participaram do teste sensorial 70 provadores não treinados, sendo crianças devidamente matriculadas em uma Escola Municipal de Guarapuava, PR, de ambos os gêneros, com idade entre 7 a 10 anos. Os alunos provaram as formulações em uma sala da escola, de forma individual, sendo que o provador foi orientado pelas pesquisadoras para o preenchimento das respostas.

Foram avaliados os atributos de aparência, aroma, sabor, textura e cor, por meio de uma escala hedônica facial estruturada mista de 7 pontos variando de 1 ("super ruim") a 7 ("super bom"). Também, foram aplicadas questões de aceitação global e intenção de compra analisadas com o uso de uma escala estruturada de 5 pontos (1- "desgostei muito" / "não compraria" a 5- "gostei muito" /“compraria com certeza") (DUTCOSKY, 2013). 
Cookies de aveia adicionados de farinha da casca de abobrinha: análise físico-química e sensorial entre crianças

Os julgadores receberam uma porção de cada amostra (aproximadamente $10 \mathrm{~g}$ ), em pratos plásticos descartáveis brancos, codificados com números de três dígitos, de forma casualizada e balanceada, acompanhados de um copo de água para a limpeza do palato. As formulações foram oferecidas aos julgadores de forma monádica sequencial. O cálculo do Índice de Aceitabilidade (IA) foi realizado segundo a fórmula: $I A(\%)=A \times 100 / B$ ( $A$ = nota média obtida para o produto; $B=$ nota máxima dada ao produto) (TEIXEIRA; MEINERT; BARBETTA, 1987).

As seguintes análises físico-químicas foram realizadas em triplicata na FCA, na formulação padrão e naquela com maior teor de FCA e com aceitação sensorial semelhante à padrão: Umidade: determinada em estufa a $105^{\circ} \mathrm{C}$ até peso constante; Cinzas: analisadas em mufla $\left(550^{\circ} \mathrm{C}\right)$; Lipídios totais: utilizou-se o método de extração a quente com extrator de Soxhlet e éter de petróleo; Proteínas: avaliadas através do teor de nitrogênio total da amostra, pelo método Kjeldahl, determinado ao nível semimicro (AOAC INTERNATIONAL, 2011). Utilizou-se o fator de conversão de nitrogênio para proteína de 6,25; Fibra bruta: mensurada por cálculo teórico (NÚCLEO DE ESTUDOS E PESQUISAS EM ALIMENTAÇÃO [NEPA], 2011; NYAM et al., 2013); Carboidratos: realizada avaliação por meio de cálculo teórico (por diferença) nos resultados das triplicatas, conforme a fórmula: \% Carboidratos $=100$ - (\% umidade $+\%$ proteína + \% lipídios + \% cinzas + \% fibra); Valor calórico total (kcal): calculado teoricamente utilizando-se os seguintes valores: lipídios (8,37 kcal/g), proteína (3,87 kcal/g) e carboidratos (4,11 kcal/g) (MERRILL; WATT, 1973).

O Valor Diário Recomendado (VD) foi calculado em relação a $30 \mathrm{~g}$ da amostra, com base nos valores médios, preconizados para crianças de 7 a 10 anos, conforme a Dietary Reference Intakes (DRI, 2005), resultando em: $2.038,17 \mathrm{kcal} / \mathrm{dia}, 278,03 \mathrm{~g} /$ dia de carboidratos, 71,21 g/dia de proteínas e $74,83 \mathrm{~g} /$ dia de lipídios.

Os dados foram analisados com auxílio do software Statgraphics Plus ${ }^{\circledR}$, versão 5.1, por meio da análise de variância (ANOVA). A comparação de médias foi realizada pelo teste de médias de Tukey e t de student, avaliados com nível de $5 \%$ de significância.

A pesquisa foi aprovada pelo Comitê de Ética em Pesquisa da Universidade Estadual do Centro-Oeste (UNICENTRO), parecer número 
n. 608.950/2014. Como critérios de exclusão foram considerados os seguintes fatores: possuir alergia a algum ingrediente utilizado na elaboração dos cookies, não ser aluno da escola em questão ou não entregar o Termo de Consentimento Livre e Esclarecido (TCLE) assinado pelo responsável legal.

\section{RESULTADOS E DISCUSSÃO}

Por meio da Tabela 1, verificam-se os resultados da avaliação sensorial das formulações de cookies padrão e daquelas adicionadas de FCA.

Tabela 1 - Médias do Índice de Aceitabilidade (IA) e dos testes sensoriais afetivos e de intenção de compra, realizados para as formulações de cookie padrão (F1) e com 5\% (F2), 10\% (F3), 15\% (F4) e 20\% (F5) de Farinha da Casca de Abobrinha (FCA)

\begin{tabular}{|c|c|c|c|c|c|}
\hline Formulações/ & F1 & F2 & F3 & F4 & F5 \\
\hline Atributos & Média $\pm E P M$ & Média土EPM & Média土EPM & Média $\pm E P M$ & Média \pm EPM \\
\hline Aparência & $6,04 \pm 0,12^{a}$ & $5,47 \pm 0,14^{a}$ & $4,76 \pm 0,19^{b}$ & $4,66 \pm 0,19^{b}$ & $4,27 \pm 0,20^{b}$ \\
\hline IA (\%) & 86,28 & 78,14 & 68,00 & 66,57 & 61,00 \\
\hline Aroma & $6,08 \pm 0,13^{a}$ & $5,61 \pm 0,14^{a}$ & $4,86 \pm 0,20^{b}$ & $4,89 \pm 0,19^{b}$ & $4,66 \pm 0,22^{b}$ \\
\hline IA (\%) & 86,86 & 80,14 & 69,43 & 69,86 & 66,57 \\
\hline Sabor & $6,42 \pm 0,11^{a}$ & $5,92 \pm 0,16^{a}$ & $4,84 \pm 0,22^{b}$ & $4,43 \pm 0,24^{b}$ & $4,20 \pm 0,24^{b}$ \\
\hline IA (\%) & 91,71 & 84,57 & 69,14 & 63,28 & 60,00 \\
\hline Textura & $6,14 \pm 0,13^{a}$ & $5,70 \pm 0,15^{a}$ & $4,97 \pm 0,19^{b}$ & $4,88 \pm 0,21^{b}$ & $4,96 \pm 0,18^{b}$ \\
\hline IA (\%) & 87,71 & 81,43 & 71,00 & 69,71 & 70,86 \\
\hline Cor & $6,07 \pm 0,14^{a}$ & $5,46 \pm 0,18^{a}$ & $5,68 \pm 0,21^{b}$ & $4,57 \pm 0,19^{b}$ & $4,37 \pm 0,22^{b}$ \\
\hline IA (\%) & 86,71 & 78,00 & 81,14 & 65,28 & 62,43 \\
\hline Aceitação global & $4,51 \pm 0,08^{a}$ & $4,21 \pm 0,10^{a}$ & $3,63 \pm 0,14^{b}$ & $3,57 \pm 0,15^{b}$ & $3,38 \pm 0,15^{b}$ \\
\hline IA (\%) & 90,20 & 84,20 & 72,60 & 71,40 & 67,60 \\
\hline $\begin{array}{l}\text { Intenção de } \\
\text { compra }\end{array}$ & $4,40 \pm 0,12^{\mathrm{a}}$ & $3,98 \pm 0,12^{\mathrm{ab}}$ & $3,51 \pm 0,16^{b c}$ & $3,53 \pm 0,16^{b c}$ & $3,30 \pm 0,16^{c}$ \\
\hline IA (\%) & 88,00 & 79,60 & 70,20 & 70,60 & 66,00 \\
\hline
\end{tabular}

* Letras diferentes na linha indicam diferença significativa pelo teste de Tukey $(p<0,05)$; EPM: erro padrão da média.

Maiores notas foram verificadas para as amostras F1 e F2 $(p<0,05)$ para todos os atributos e para a aceitação global, sendo que não houve diferença estatística entre as demais formulações. Resultados semelhantes foram 
Cookies de aveia adicionados de farinha da casca de abobrinha: análise físico-química e sensorial entre crianças

observados por Nyam, Lau e Tan (2013), que avaliaram a aceitabilidade de pães adicionados de $\mathrm{FCA}(0,5$ e 10\%), entre adultos. A menor aceitação das formulações F3, F4 e F5 pode ser justificada pela maior concentração de aminoácidos provenientes da casca de abobrinha. Alguns desses aminoácidos, que se apresentam na forma de isômero $L$, podem desencadear um sabor amargo à FCA (FOOD INGREDIENTS BRASIL [FIB], 2014), exemplos são a arginina (1,12 mg/kg), histidina $(0,78 \mathrm{mg} / \mathrm{kg})$, leucina $(0,63 \mathrm{mg} / \mathrm{kg})$, isoleucina $(0,59 \mathrm{mg} / \mathrm{kg})$, valina $(0,58 \mathrm{mg} / \mathrm{kg})$, fenilalanina $(0,41 \mathrm{mg} / \mathrm{kg})$, tirosina $(0,27 \mathrm{mg} / \mathrm{kg})$ e metionina $(0,05 \mathrm{mg} / \mathrm{kg})(\mathrm{KIM}$ et al., 2012$)$.

A FCA apresentou uma coloração esverdeada, o que alterou também a aparência e a cor dos cookies contendo esse ingrediente. Esse efeito justifica a menor preferência das formulações com maiores teores de FCA (F3, F4 e F5). A cor verde da casca de abobrinha se deve à presença de clorofila (TAIZ; ZEIGER, 2013), que é encontrada em concentrações próximas a 1,06 $\mathrm{mg} \mathrm{g}^{-1}$ (ARAÚJO, 2014).

A alteração do aroma nas amostras F3, F4 e F5 está associada aos compostos voláteis presentes nas hortaliças como, por exemplo, os ésteres, álcoois, ácidos e compostos carbonil (WILLS et al., 1998). Além disso, a presença do $\beta$-caroteno $(39,48 \mathrm{mg} / \mathrm{kg})$ na casca de abobrinha também pode colaborar para a alteração do aroma, já que provém da degradação enzimática dos carotenoides (LEWINSON et al., 2005). Para a intenção de compra, houve maior preferência para F1 comparada à F3, F4 e F5 $(p<0,05)$, enquanto F2 apresentou maiores notas que F5. As formulações F1 e F2; F2, F3 e F4 e; F3, F4 e F5 apresentaram intenção de compra semelhante entre si $(p>0,05)$. Durante o preparo das formulações, percebeu-se que aquelas com maiores teores de FCA apresentaram um aspecto mais quebradiço, modificando a textura dos produtos. $\mathrm{O}$ alto teor de fibras presente na casca da abobrinha pode explicar essas modificações, visto que alteram as propriedades viscoelásticas, devido à retenção hídrica e redução de elasticidade da massa (KATINA et al., 2006; KIM et al., 2012).

De acordo com Teixeira, Meinert e Barbetta (1987), um IA superior a $70 \%$ classifica o produto com boa aceitabilidade sensorial. Em geral, as formulações F1 e F2 foram as que apresentaram maiores IA. Apesar disso, constata-se que os resultados presentes na pesquisa são favoráveis, uma 
vez que talos, cascas e folhas de vegetais possuem elevados teores de fibras (FERRARI, 2012). Além do mais, o aumento no consumo de vegetais fontes de fibras está associado à redução do risco de doenças cardiovasculares e de câncer, especialmente do trato gastrointestinal. Também, promove o aumento no volume das fezes e acelera o trânsito intestinal (CUERVO et al., 2013). Na Figura 1, está representada a distribuição dos provadores pelos valores hedônicos avaliados no teste sensorial.
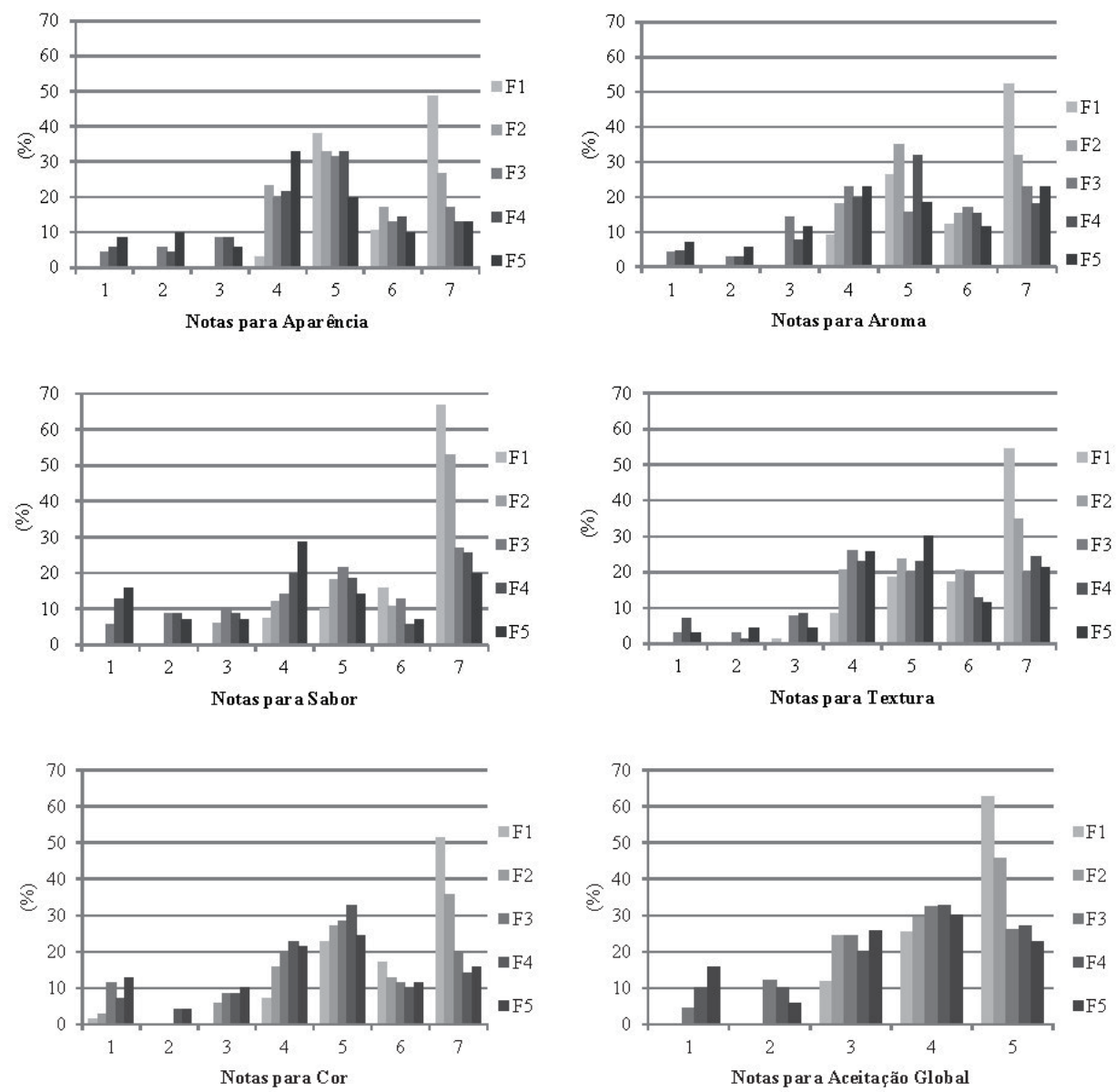

Figura 1 - Distribuição dos provadores pelos valores hedônicos obtidos na avaliação dos atributos aparência, aroma, sabor, textura, cor e aceitação global das formulações de cookie padrão (F1) e com 5\% (F2), $10 \%$ (F3), 15\% (F4) e 20\% (F5) de Farinha da Casca de Abobrinha (FCA) 
Cookies de aveia adicionados de farinha da casca de abobrinha: análise físico-química e sensorial entre crianças

A maioria das notas conferidas pelos provadores para os atributos foram superiores a 5 (bom) e 4 (gostei) para aceitação global, o que indica que as formulações, em geral, apresentaram boa aceitabilidade. Exceção para a amostra F5, que concentrou a maioria das notas abaixo de 4 (talvez bom/talvez ruim) para as características de aparência e sabor. Conforme Ferrari (2012), os produtos adicionados de ingredientes diferenciados apresentam, geralmente, alta aceitabilidade. Esse fato pode contribuir para melhorar a alimentação de crianças. Isso, porque o consumo de nutrientes mais saudáveis como as vitaminas, minerais e fibras, pode promover diversos benefícios à saúde (CUERVO et al., 2013).

A amostra F2 foi aquela com maior teor de FCA e aceitação similar a padrão (F1) em todos os testes sensoriais avaliados (Tabela 1); diante disso, ambas foram consideradas para fins de comparação na presente pesquisa. Por meio da Tabela 2, observa-se a composição físico-química e os Valores Diários Recomendados (VD) do cookie padrão e daquele acrescido de 5\% de FCA.

Tabela 2 - Composição físico-química da Farinha da Casca de Abobrinha (FCA) do cookie padrão (F1) e daquele adicionado de 5\% de FCA (F2) e Valores Diários Recomendados - VD* (porção média de 30 gramas - 6 unidades)

\begin{tabular}{|c|c|c|c|c|c|}
\hline \multirow{2}{*}{ Avaliação } & \multirow{2}{*}{$\begin{array}{c}\text { FCA } \\
\text { Média } \pm D P\end{array}$} & \multicolumn{2}{|l|}{ F1 } & \multicolumn{2}{|l|}{$\mathbf{F} 2$} \\
\hline & & Média $\pm D P$ & VD $(\%)^{*}$ & Média $\pm D P$ & VD $(\%)^{*}$ \\
\hline Umidade (\%) & $3,60 \pm 0,07$ & $0,94 \pm 0,02^{b}$ & ND & $1,41 \pm 0,02^{a}$ & ND \\
\hline Cinzas $\left(\text { g. } 100 \mathrm{~g}^{-1}\right)^{* *}$ & $9,78 \pm 0,06$ & $1,64 \pm 0,04^{b}$ & ND & $2,42 \pm 0,02^{a}$ & ND \\
\hline Proteínas (g.100g-1)** & $25,93 \pm 0,02$ & $9,83 \pm 0,05^{b}$ & 4,14 & $11,68 \pm 0,01^{\mathrm{a}}$ & 4,92 \\
\hline Lipídios (g.100g $\left.\mathrm{g}^{-1}\right)^{* *}$ & $9,75 \pm 0,09$ & $26,00 \pm 0,04^{b}$ & 11,33 & $27,81 \pm 0,04^{a}$ & 11,15 \\
\hline Carboidratos $\left(\mathrm{g} .100 \mathrm{~g}^{-1}\right)^{* *}$ & $50,94 \pm 0,74$ & $61,59 \pm 0,56^{a}$ & 6,65 & $56,68 \pm 0,38^{b}$ & 6,12 \\
\hline Calorias $\left(\mathrm{kcal} 100 \mathrm{~g}^{-1}\right)^{* *}$ & $391,28 \pm 1,25$ & $508,78 \pm 1,65^{b}$ & 7,49 & $510,95 \pm 1,45^{a}$ & 7,52 \\
\hline Fibra (g.100g $\left.{ }^{1}\right)$ & $14,83 \pm 0,96^{f}$ & $3,45^{\alpha}$ & ND & $4,08^{\alpha}$ & ND \\
\hline
\end{tabular}

Letras distintas na linha entre F1 e F2 indicam diferença significativa pelo teste de t de student $(p<0,05)$; *VD: nutrientes avaliados pela média da DRI (2005), com base numa dieta de 2.038,17

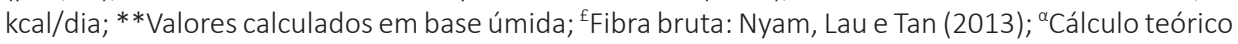
de fibra bruta/alimentar: Nyam, Lau e Tan (2013); NEPA (2011); DP: desvio padrão da média; ND: não disponível. 
Nyam, Lau e Tan (2013), avaliando casca de abobrinha, verificaram resultados superiores de umidade $(5,96 \%)$, inferiores de cinzas $(0,41 \%)$, proteínas $(23,89 \%)$, lipídios $(5,77 \%)$ e similares de carboidratos $(49,11 \%)$. Essas diferenças se justificam pelas diferenças no estado de maturação dos frutos, forma de armazenamento, processamento, etc. (BHOWMIK; PAN, 1992; ROMOJARO; MARTÍNEZ-MADRID; HIDALGO, 1996). O teor de cinzas constatado na FCA demonstra a elevada concentração de minerais do produto. Além disso, o alto conteúdo de fibras presente na FCA pode contribuir para uma alimentação mais adequada na infância, já que as fibras regulam o hábito intestinal, melhoram a absorção de nutrientes e a produção de enzimas (CHRISTIE et al., 2002; PORTELA, 2009). A FCA apresentou teor de umidade conforme o recomendado pela RDC n. 263 (máximo 15\%), referente aos Produtos de Cereais, Amidos, Farinhas e Farelos (BRASIL, 2005). Contudo as farinhas não podem ser consideradas fontes proteicas (BRASIL, 2012).

A amostra F2 apresentou maiores teores de umidade que F1. Isto se deve à presença de fibras na FCA, as quais possuem propriedades higroscópicas que retêm água (FIORDA et al., 2013). Resultados similares foram descritos por Nyam, Lau e Tan (2013) avaliando a adição de 5\% de FCA em pães. Conforme a Resolução n. 12 de julho de 1978 (BRASIL, 1978), o teor máximo de umidade para biscoitos é de 14,0\%; dessa forma, as amostras F1 e F2 estão dentro do recomendado pela legislação brasileira.

Maiores teores de cinzas, proteínas, lipídios e calorias $(p<0,05)$ foram constatados em $\mathrm{F} 2$, o que pode ser explicado devido à farinha de trigo apresentar menores concentrações desses nutrientes (0,8 g/100 g, 9,8 g/100 $\mathrm{g}, 1,4 \mathrm{~g} / 100 \mathrm{~g}$ e $360 \mathrm{kcal} / 100 \mathrm{~g}$, respectivamente) (NEPA, 2011), quando comparada à FCA (Tabela 2). Entretanto a formulação F1 apresentou maiores teores de carboidratos que $\mathrm{F} 2$, já que a farinha de trigo contém maiores conteúdos de carboidratos $(75,1 \mathrm{~g} / 100 \mathrm{~g})$ que a FCA.

Destaca-se como principal resultado deste trabalho o teor de fibras verificado na formulação adicionada de $5 \%$ de FCA (F2), expressando um aumento significativo de $18,26 \%$ em relação à $F 1$. Isso se deve, principalmente, ao elevado teor de fibras presente na FCA (14,83 g/100 g) (NYAM; LAU; TAN, 2013), bem superior ao encontrado na farinha de trigo (2,3 g/100 g) (NEPA, 2011). Efeitos semelhantes foram observados por Nyam, Lau e Tan 
Cookies de aveia adicionados de farinha da casca de abobrinha: análise físico-química e sensorial entre crianças

(2013), que obtiveram um aumento de $30 \%$ no teor de fibras com adição de $5 \%$ de FCA em pães.

\section{CONCLUSÃO}

Um nível de adição de até $5 \%$ de FCA em cookies foi bem aceito pelos provadores, obtendo-se aceitação sensorial semelhante ao produto padrão. Além disso, proporcionou um aumento no aporte de umidade, cinzas, proteínas, lipídios, calorias e fibras, porém reduziu o teor de carboidratos melhorando o perfil nutricional do produto. Assim, a FCA pode ser considerada um potencial ingrediente para adição em cookies e similares, com possibilidade de ser oferecida ao público infantil e com altas expectativas de comercialização.

\section{REFERÊNCIAS}

AOAC INTERNATIONAL. Official Methods of Analysis of AOAC International. 18. ed. Gaithersburg: AOAC, 2011.

ARAÚJO, F. F. Alterações pós-colheita e resposta ao etileno em frutos de abobrinha "menina brasileira". 2014. 57f. Dissertação (Mestrado em Fitotecnia)- Universidade Federal de Viçosa (UFV), Viçosa, MG, 2014.

ASSOCIAÇÃO BRASILEIRA DAS INDÚSTRIAS DE BISCOITOS, MASSAS ALIMENTÍCIAS E PÃES E BOLOS INDUSTRIALIZADOS (ABIMAPI). Categorias de biscoitos, massas alimentícias, pães e bolos industrializados fecham 2015 com faturamento de $R S$ 35,4 bilhões. 28 mar. 2016. Disponível em: <https://www.abimapi.com.br/noticiasdetalhe.php?i=MTc10Q==>. Acesso em: 2 jun. 2017.

BHOWMIK, S. R.; PAN, A. J. C. Shelf life of mature green tomatoes stored in controlled atmosphere and high humidity. Journal of Food Science, Chicago, v. 57, n. 4, p. 948-95, jul. 1992.

BRASIL. Ministério da Saúde. Agência Nacional de Vigilância Sanitária (ANVISA). Resolução RDC n. 54, de 12 de novembro de 2012. Regulamento técnico Mercosul sobre informação nutricional complementar (declarações de propriedades nutricionais). Diário Oficial União, Poder Executivo, Brasília, DF, 2012.

. Ministério da Saúde. Agência Nacional de Vigilância Sanitária (ANVISA). Resolução RDC n. 263, de 22 de setembro de 2005. Regulamento Técnico para produtos de cereais, amidos, farinhas e farelos. Diário Oficial União, Poder Executivo, Brasília, DF, 2005. 
- Ministério da Saúde. Agência Nacional de Vigilância Sanitária (ANVISA). Resolução CNNPA n. 12, de julho de 1978. Normas técnicas especiais relativas a alimentos (e bebidas). Diário Oficial da União, Poder Executivo, Brasília, DF, 1978.

CHRISTIE, L.; HINE, R. J.; PARKER, J. G.; BURKS, W. Food allergies in children affect nutrient intake and growth. Journal of the American Dietetic Association, Chicago, v. 102, n. 11, p. 1648-51, nov. 2002.

CUERVO, A.; SALASAR, N.; RUAS-MADIEDO, P.; GUEIMONDE, M.; GONZÁLEZ, S. Fiber from a regular diet is directly associated with fecal short-chain fatty acid concentrations in the elderly. Nutrition Research, New York, v. 33, n. 10, p. 811-6, out. 2013.

DIETARY REFERENCE INTAKES (DRI). Dietary Reference Intakes for energy, carbohydrate, fiber, fat, fatty acids, cholesterol, protein and amino acids. Washington: National Academy Press, 2005.

DUTCOSKY, S. D. Análise sensorial de alimentos. Curitiba: Champagnat, 2013.

FERRARI, A. C. Influência familiar na alimentação infantil. 2012. 14f. Monografia (Especialização em Nutrição Clínica) - Universidade Regional do Noroeste do Estado do Rio Grande do Sul (UNIJUI), Ijuí, RS, 2012.

FIORDA, F. A.; SOARES JÚNIOR, M. S.; SILVA, F. A.; SOUTO, L. R. F.; GROSSMANN, M. V. E. Farinha de bagaço de mandioca: aproveitamento de subproduto e comparação com fécula de mandioca. Pesquisa Agropecuária Tropical, Goiânia, v. 43, n. 4, p. 408-16, out./dez. 2013.

FOOD INGREDIENTS BRASIL (FIB). Os aminoácidos e o sabor. Food Ingredients Brasil, v. 16, n. 31, p. 70-6, 2014.

KATINA, K.; SALMENKALIO-MARTTILA, M.; PARTANEN, R.; FORSSELL, P.; AUTIO, $K$. Effects of sourdough and enzymes on staling of high-fibre wheat bread. Food Science and Technology, London, v. 39, n. 5, p. 479-91, jun. 2006.

KIM, M. Y.; KIM, E. J.; KIM, Y. N; CHANGSUN, C.; BOG-HIEU, L. Comparison of the chemical compositions and nutritive values of various pumpkin (Cucurbitaceas) species and parts. Nutrition Research and Practice, Seoul, v. 6, n. 1, p. 21-7, fev. 2012.

LEWINSOHN, E.; SITRIT, Y.; BAR, E.; AZULAY, Y.; IBDAH, M.; MEIR, A.; YOSEF, E.; ZAMIR, D.; TADMOR, Y. Not just colors- carotenoid degradation as a link between pigmentation and aroma in tomato and watermelon fruit. Food Science \& Tecnhology, London, v. 16, n. 9, p. 407-15, set. 2005.

MERRILL, A. L.; WATT, B. K. Energy value of foods: basis and derivation. Washington: USDA, 1973. (Agricultural Handbook, n. 74).

NYAM, K. L.; LAU, M.; TAN, C. P. Fibre from Pumpkin (Cucurbita pepo L.) seeds and rinds: physico-chemical properties, antioxidant capacity and application as bakery 
Cookies de aveia adicionados de farinha da casca de abobrinha: análise físico-química e sensorial entre crianças

product ingredients. Malaysian Journal of Nutrition, Kuala Lumpur, v. 19, n. 1, p. 99-109, abr. 2013.

ORGANIZAÇÃO DAS NAÇÕES UNIDAS PARA A ALIMENTAÇÃO E A AGRICULTURA (FAO). Desperdício de alimentos tem consequências no clima, na água, na terra e na biodiversidade. 2013. Disponível em: <https://www.fao.org.br/daccatb.asp>. Acesso em: 8 jan. 2017.

PORTELA, J. V. F. Estudo dos aspectos tecnológicos e de qualidade envolvidos no aproveitamento da casca e da polpa da melancia (citrullus lanatus schrad). 2009. 132f. Dissertação (Mestrado em Ciência e Tecnologia de Alimentos) - Universidade Federal da Paraíba (UFPB), João Pessoa, PB, 2009.

ROMOJARO, F.; MARTÍNEZ-MADRID, M. C.; HIDALGO, F. S. Nuevas tecnologías de conservación de frutas y hortalizas: atmosferas modificadas. Madri: Mundi-prensa, 1996.

PARANÁ (Estado). Secretaria de Estado da Agricultura e do Abastecimento (SEAB). 2013. Olericultura - análise da conjuntura agropecuária. 2013. Disponível em: <http://www.agricultura.pr.gov.br/arquivos/File/deral/Prognosticos / olericultura_2012_13.pdf>. Acesso em: 10 jan. 2017.

NÚCLEO DE ESTUDOS E PESQUISAS EM ALIMENTAÇÃO (NEPA). Tabela Brasileira de Composição dos Alimentos (TACO). 4. ed. Campinas, SP: NEPA/UNICAMP, 2011.

TAIZ, L.; ZEIGER, E. Fisiologia vegetal. 3. ed. Porto Alegre: Artmed, 2013.

TEIXEIRA, E.; MEINERT, E. M.; BARBETTA, P. A. Análise sensorial de alimentos. Florianópolis: Editora UFSC, 1987.

WILLS, R.; McGLASSON, B.; GRAHAM, D.; JOYCE, D. Postharvest: an introduction to the physiology \& handling of fruit, vegetables \& ornamentals. 4. ed. Wallingford: CAB International, 1998. 
